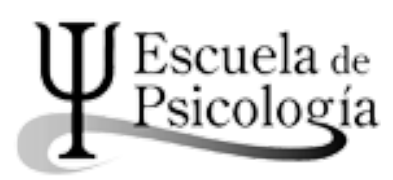

Wímblu, Rev. estudiantes Esc. de psicología, Univ. de Costa Rica. 12 (2): 87-92, 2017 / ISSN: 1659-2107

\title{
Night of the Living Dead y la contumaz perseverancia de la carne ${ }^{1}$
}

Night of the Living Dead and the contumacious perseverance of meat

Camilo Retana*

Resumen: El zombie, al menos a partir de la figura que inaugura George A. Romero, constituye una metáfora política. Romero, en efecto, subvierte la pasividad del rebaño hambriento por una monstruosidad que interpela al espectador y su contexto, en tanto trasciende el plano de la criatura extraña hasta una alteridad, por momentos, demasiado idéntica. El golpe estético está precisamente en devolver lo abyecto, lo expulsado como anormal de sí. El zombie romeriano da sustento a una rebelión encarnada contra estatutos morales, higiénicos, estéticos, políticos. Poniendo entre signos de interrogación la pureza de la vida (biopoder eugenésico) y a la inevitabilidad e irreversibilidad de la muerte, el lugar de resistencia zombie es el cuerpo.

Palabras clave: zombi, cuerpo, cine.

Abstract: The zombie, at least the figure inaugurated by George A. Romero's films, constitutes a political metaphor. Romero, indeed, subverts the passivity of the hungry herd for a monstrosity that challenges the viewer and their context, while transcending the plane of that strange creature to an alterity, at times, too similar. The aesthetic shock lies precisely in returning the abjectedness of oneself, the abnormal which was expelled. The Romerian zombie gives sustenance to a rebellion embodied against moral, hygienic, aesthetic, and political statutes. By questioning the purity of life (eugenics biopower) and the inevitability and irreversibility of death, the place for the zombie resistance is the body.

Key Words: zombie, body, cinema.

Universidad de Costa Rica. Doctor en Filosofía. Costa Rica.

Correo electrónico: camiloretana@hotmail.com

Recepción:28/3/2017 Aceptación: 22/8/2017 
Todos volvieron hacia Neville unos rostros pálidos. Neville los observó serenamente. Y de pronto comprendió. Yo soy el anormal ahora. La normalidad es un concepto mayoritario. Norma de muchos. No de un solo hombre.

Soy leyenda, Richard Matheson, p. 179

Es el 2 de octubre de 1968 y el ejército mexicano abre fuego contra miles de manifestantes en la plaza de Tlatelolco, en México. Unos meses antes, durante la primavera de Praga, las multitudes se manifestaban alrededor del mundo contra la ocupación soviética en Checoslovaquia. En mayo de ese mismo año, en Francia, 9 millones de obreros entraban en huelga y miles de estudiantes tomaban por asalto la Universidad de La Sorbona, al tiempo que más de 200.000 manifestantes abarrotaban las calles de París. Entretanto, un neófito director nerd neoyorkino, exrecadero de Hitchcock durante la filmación de Con la muerte en los talones y realizador de bizarras pautas comerciales en las que, por ejemplo, un equipo de científicos entraba al interior de una lavadora en un submarino microscópico para encontrar la fuente de la suciedad en las camisas ${ }^{1}$ filmaba una película extraña, casi malograda, obtusa, pero que cambiaría la imaginación política del cine de terror contemporáneo. Me refiero a Night of the Living Dead.

Según el propio Romero, las rebeliones de la época estaban en el centro de aquella película. El filme, afirma,

era acerca de la revolución, era acerca de las nuevas generaciones tomando el lugar de las viejas. El concepto era que se venía una revolución y un nuevo mundo. A finales de los sesenta la gente aspiraba a cambiar el mundo (...). Yo traté de usar eso.

La noche que terminamos la película, la metimos en el auto y viajamos a New York a ver si alguien queria estrenarla. Y esa noche, mientras viajábamos en el auto, escuchamos en la radio que Martin Luther King habia sido asesinado. Estábamos todos muy enojados. Con todo, con la guerra de Vietnam, con la idea de que nuestra opinión no contaba (...). Así que ese fue el mensaje que teníamos en mente en aque momento (citado en Saracino, 2009, p. 41).

Rebelarse en contra del poder político: la premisa, sin duda, requería inventar un nuevo tipo de metáfora para la que ninguno de los monstruos del pasado daba a vasto. El zombi de Romero marca, de hecho, un punto de inflexión con una serie de representaciones acerca de lo monstruoso propias de la cultura de masas. Subrayemos dos de esas rupturas.

En primer término, el zombi romeriano se escinde de la tradición vampiresca de la cual proviene: su genealogía difiere esencialmente de la del vampiro toda vez que lo que en este es estirpe y mito, en el zombi es infección y contagio. Las formulaciones más actuales del zombi siguen la tradición abierta por Night of the Living Dead precisamente en cuanto el zombi es cada vez menos un muerto viviente y cada vez más un cuerpo que ha sido tomado por una enfermedad o una infección. En segunda instancia, el monstruo de Romero ya no es el zombi exótico del vudú haitiano, ni tampoco el marciano invasor del cine de terror de la época -metáfora del enemigo soviético que hoy encontramos reensamblado en clave xenófoba en el cine de acción, en el que los villanos del Medio Oriente secuestran, matan y atentan contra el modo de vida estadounidense-. Es cierto que en la película de Romero se especula con el origen extraterrestre de la infección, pero lo importante está en otra parte, a saber, en el origen sociocultural de la hecatombe: son la CIA, la NASA y el FBI, su secretismo y su actuar a las espaldas de la sociedad civil, lo que origina el desastre. En todo caso, lo importante de esta segunda ruptura romeriana con la otredad exotizada del vudú y con la alteridad del marciano comunista es el hecho de que el zombi de Night of the Living Dead constituye un tipo de alteridad completamente distinto. El tipo de otredad que interesa a Romero es, en efecto, una otredad paradójicamente vecina, cercana; una que evoca antes lo anormal que lo ajeno, antes lo distinto por cercano, que lo radicalmente Otro. No por casualidad la película transcurre al interior de una bucólica cabaña alejada en el campo, con todas las resonancias simbólicas que dicho tipo de edificaciones posee en el contexto del american way of life. Pero más importante aún es el hecho de que el monstruo romeriano nos confronta como nunca antes con nuestra propia diferencia: el monstruo de Romero habita dentro de nosotros mismos y lo que en verdad constituye la amenaza no es el zombi propiamente dicho, sino la forma en que percibimos y nos relacionamos con lo otro (ya sea con lo otro de carne y hueso o con lo otro excluido de nuestra propia psique).

En tal sentido, el zombi condensa política y estéticamente hablando el temor a la anormalidad. En una palabra, el otro romeriano no es, paradójicamente, un extraño, sino, por el contrario, una figura familiar que, en virtud del efecto desencadenado por la hecatombe zombi, ha hecho emerger de sí aquello que debería haber mantenido a raya (el rasgo más grotesco del zombi es, en efecto, el hecho de que en su cuerpo todo lo que debería estar adentro -en cuenta vísceras y tripas- se encuentra afuera). En palabras de Jazmín Acosta, con el zombi "eso que se me aparece, puedo ser yo, mañana, cuando ya no esté. Ese otro, de hecho, seré yo un día, en la tumba" (p. 24). La monstruosidad del zombi deviene tal por causa de su similitud conmigo y no por causa de su diferencia. Lo auténticamente horripilante del zombi es precisamente que, siendo como yo, se niega ser un cuerpo "normal" (¿como el mío?). El zombi es la negación radical de alma y de toda la metafísica cristiana. En breve, el zombi es la abyección pura porque nos recuerda la contumaz perseverancia de la carne: la manera en que el cuerpo se venga de todo aquello que lo niega, en cuenta las normativas que pretenden civilizarlo.

El problema de la anormalidad aparece, de hecho, en otro relato fundante del género (inspirador, por cierto, de Night of the Living Dead). Me refiero a 
Soy leyenda, la novela de Richard Matheson citada al inicio y adaptada al cine en sucesivas versiones, la más conocida de las cuales es la dirigida por Francis Lawrence y protagonizada por Will Smith. En dicha novela, a medio camino aún entre la tradición vampirezca y el género zombi, el último hombre de la tierra se enfrenta a una horda de enloquecidos zombis que orbitan fuera de su casa (de nuevo se trata de la metáfora del hogar como reducto último de la subjetividad burguesa). La historia de Matheson es interesante en relación con la ópera prima de Romero (supuestamente inspirada en aquella) por una razón: en ambos relatos la pregunta fundamental es por el modo en que la identidad se consuma sobre un fondo de omisiones (cosas que es menester olvidar de mí y de mi pasado para poder seguir siendo un yo viable), rechazos (cosas que es menester repudiar en los otros en la medida en que cuestionan la naturalidad de mis rasgos identitarios) y agresiones (actos que debo llevar a cabo en contra de aquellos que cuestionan mi propio ser). Tanto para Matheson como para Romero el problema de la anormalidad no es estadístico, sino simbólico u ontológico (como lo es para Hershel, el personaje de The Walking Dead que compara la violencia en contra de los zombis con la violencia en contra de los locos); a saber, el zombi constituye la encarnación de aquello que negamos en nosotros mismos... el zombi es nuestra némesis hecha carne.

Creo, en efecto, que lo que tendríamos que preguntarnos seriamente es si el hecho de que los zombis sean metáforas corpóreas de la anormalidad no pone en suspenso el estatuto de los héroes y villanos en Night of the Living Dead. ¿Son acaso acá los vivos los buenos de la película? No puedo dejar de notar el hecho de que son los agentes policiales del Estado, incitados por los altos mandos del FBI y la CIA, los que se encargan de aplacar la insurrección de los muertos. En otras palabras: si los zombis se levantan contra las prescripciones biológicas (pues los muertos no deberían resucitar), institucionales (puesto que los zombis desatienden las prescripciones higiénicas y estéticas), antropológicas (en la medida en que los monstruos romerianos desobedecen la prohibición arcaica de la antropofagia) y morales (pues renuncian a la calma del interior y las comodidades del hogar en busca de un exterior abierto tan incierto como amenazante -espacialidad arquitectónica que según Richard Sennet es propia de la sensibilidad política de la izquierda desde la Revolución Francesa-) la acción policial de asesinar a los abyectos responde a la necesidad de salvaguardar la normalidad social. Los últimos planos de la película, en los que los agentes del orden acribillan a las turbas de zombis en el espacio abierto, no puede dejar de tener resonancias políticas si tomamos en cuenta el contexto político al que aludí al inicio.

Sin embargo, el gesto fílmico decisivo desde la lectura que quisiera proponer es el de matar a Ben junto a los zombis. Leído en el contexto sesentista, el hecho de que Ben, el protagonista de la cinta, un negro que daba órdenes a una ristra de estúpidos blancos incapaces de sobrevivir por sí mismos, fuese asesinado a quemarropa como un muerto viviente más, ubica a dicho personaje como una especie de superhombre ajeno a la normalidad blanca y biempensante a la que se dirige la voz en la radio, esa misma que indica que lo seguro es esperar a que el gobierno resuelva la situación. A lo largo de la trama, la condición de alteridad de Ben se consolida paulatinamente. Finalmente, como hemos visto, el personaje termina siendo objetivo militar, junto a los zombis, de las fuerzas del gobierno. Ben es un negro descartable porque no se somete al orden y porque no acepta ser gobernado, por lo que debe ser quemado junto al resto de cuerpos indóciles (la referencia a la quema de brujas, esas mujeres insolentes que no aceptaban las órdenes de los buenos señores de la inquisición, no puede ser más obvia). Entretanto, la voz en los medios sigue chillando que no hay tiempo para el llanto: esos cuerpos (y cito a Romero) "van a tener que olvidar el consuelo de un funeral".

No hay tiempo para analizar todas las derivas que estos poderosos tropos instalados por Romero han tenido en las películas posteriores del género. Quiero, únicamente, concluir con una idea. Esta película, sin duda, no tiene un happy ending. Todo parece indicar que las fuerzas del Estado lograrán aplacar la rebelión de los muertos y que todo volverá a la normalidad (aunque esta lectura podría cambiar si nos atenemos a la filmografía posterior del director). No obstante, es notorio que el género zombi no ha dejado de volver, desde Romero, a la imagen de la multitud que toma el mundo por asalto en busca de la satisfacción de sus pulsiones (Cronemberg, siguiendo a un tiempo los guiños freudianos y romerianos, convertirá al zombi en una criatura ya no ávida de carne sino de sexo).

¿Cómo leer, pues, esta contumaz perseverancia de la carne? En su ensayo El monstruo político, Toni Negri ofrece una pauta para contestar esta pregunta. Contrariamente a la visión del monstruo como autómata - de esa forma lee al zombi, por ejemplo, Jorge Fernández Gonzalo en su Filosofía zombi (2009, p. 26) - Negri propone que el monstruo "está afuera de la economía del ser" (2009, p. 95) y que es la Modernidad la que permite un reingreso parcial, aunque radical, del monstruo al discurso filosófico. El monstruo/anormal propuesto por Negri está asociado a una "alternativa ontológica contra la pretensión eugenésica" (2009, p. 107). Dentro de un linaje en el que Negri ubica al comunismo campesino y al posterior comunismo obrero/industrial, el monstruo contemporáneo escenificaría la posibilidad de subversión de la vida: el polo radical en el contexto de la oposición entre biopoder eugenésico y biopolítica de la multitud. El zombi, heredero según creo de esa monstruosa tradición, se enfrenta al poder eugenésico reafirmando entonces la persistencia multitudinaria de la vida. El zombi es la metáfora de una alteridad que no obedece siquiera al perentorio llamado de la muerte. Tal y como apunta Negri,

hoy estamos no tanto en la enésima revuelta de la potencia contra el poder, sino frente a la afirmación común y a la victoria de la potencia. Hasta ayer subordinada, 
jerárquicamente clasificada, organizada por el poder, la potencia del monstruo ha asediado al poder a través de la invasión del bios. El monstruo ha devenido hegemonía política. En otras palabras, se ha infiltrado por todas partes, como un rizoma (...). Destruirlo es ahora imposible, a menos que se destruya con él el mundo. Podría suceder, pero no sucederá, [pues] el monstruo en el que nos reconocemos, con el cual identificamos nuestro destino, se sostiene en una indestructible genealogía del porvenir (2009, p. 139).

\section{Notas}

1. Texto presentado en el contexto de un cineforo sobre Night of the Living Dead organizado por la Asociasión de estudiantes de Filosofía en el 2015.

2. Para estos y otros interesantes datos biofilmográficos sobre Romero véase Pérez (2013, pp. 127- 133).

\section{Bibliografía}

Acosta, J. (2012). Espectogramas (pos)modernos: el mito zombi en el horizonte de los "post-humano". En J. Acosta et. al. Antología del ensayo filosófico joven en Argentina. Buenos Aires: Fondo de Cultura Económica.

Fernández, J. (2009). Filosofía zombi. Barcelona: Anagrama.

Matheson, R. (2008). Soy leyenda. Buenos Aires: Minotauro.

Negri, T. (2009). El monstruo político. Vida desnuda y potencia. En G. Giorgi y F. Rodríguez (comps.) Ensayos sobre biopolítica. Buenos Aires: Paidós.

Pérez, L. (2013). George A. Romero. Cuando no quede sitio en el infierno. Madrid: Akal.

Saracino, L. (2009). Una enciclopedia del cine de muertos vivos. Buenos Aires: Fan Editores.

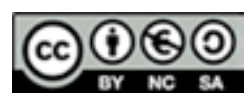

Esta obra está bajo una licencia de Creative Commons Reconocimiento

- NoComercial - CompartirIgual (by-nc-sa) 